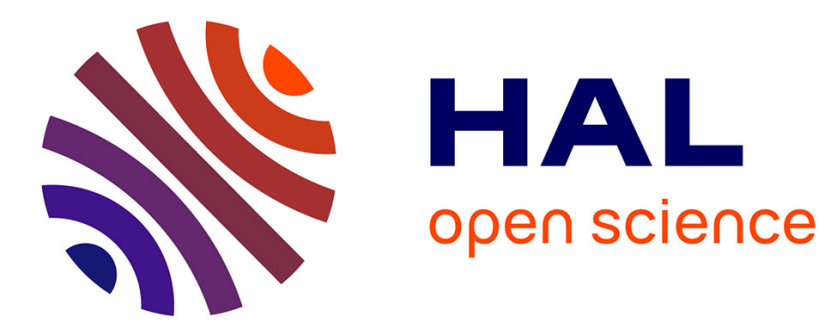

\title{
Surf zone cross-shore boundary layer velocity asymmetry and skewness: An experimental study on a mobile bed
}

Céline Berni, Eric Barthélemy, Hervé Michallet

\section{To cite this version:}

Céline Berni, Eric Barthélemy, Hervé Michallet. Surf zone cross-shore boundary layer velocity asymmetry and skewness: An experimental study on a mobile bed. Journal of Geophysical Research. Oceans, 2013, 118 (4), pp.2188-2200. 10.1002/jgrc.20125 . hal-00909152

\section{HAL Id: hal-00909152 https://hal.science/hal-00909152}

Submitted on 15 May 2020

HAL is a multi-disciplinary open access archive for the deposit and dissemination of scientific research documents, whether they are published or not. The documents may come from teaching and research institutions in France or abroad, or from public or private research centers.
L'archive ouverte pluridisciplinaire HAL, est destinée au dépôt et à la diffusion de documents scientifiques de niveau recherche, publiés ou non, émanant des établissements d'enseignement et de recherche français ou étrangers, des laboratoires publics ou privés. 


\title{
Surf zone cross-shore boundary layer velocity asymmetry and skewness: An experimental study on a mobile bed
}

\author{
C. Berni, ${ }^{1,2}$ E. Barthélemy, ${ }^{1}$ and H. Michallet ${ }^{1}$ \\ Received 28 August 2012; revised 6 February 2013; accepted 11 February 2013.
}

[1] An experimental study on a physical model of a beach in a two-dimensional wave flume was designed to investigate velocity nonlinearities in the wave boundary layer. The cross-shore velocity was measured in the surf zone along a vertical profile every $3 \mathrm{~mm}$ from free-stream elevation down to the still bed level. The skewness and the asymmetry of the phase averaged velocity were computed at each elevation. Observations indicate that the free-stream asymmetry transforms into bottom velocity skewness. A linear experimental relation between free-stream asymmetry to skewness ratio and bottom skewness to free-stream skewness ratio is established. A theoretical linear relationship is discussed, which predicts the phase lead of the bottom velocity. This phase lead is also determined by Fourier analyzing the velocity time series. The first two Fourier components yield the same phase lead at the bed that is found to be about $30^{\circ}$ and nearly constant over all the experiments made.

Citation: Berni, C., E. Barthélemy, and H. Michallet (2013), Surf zone cross-shore boundary layer velocity asymmetry and skewness: an experimental study on a mobile bed, J. Geophys. Res. Oceans, 118, doi:10.1002/jgrc.20125.

\section{Introduction}

[2] Predicting beach morphology variations is a difficult task. Many long-shore and cross-shore non-cohesive sediment transport models have been developed to this end. Contrary to long-shore transport, cross-shore transport remains hard to predict. This is partly due to the numerous competing processes involved in the destabilization and transport of the sediment bottom layer, most of which take place in the oscillatory boundary layer.

[3] Most experimental knowledge on the wave boundary layer has been generated by investigations on boundary layers on rigid bottom models with sinusoidal free-stream forcing [Jonsson and Carlsen, 1976; Sleath, 1987; Jensen et al., 1989 , for instance]. In a perfectly symmetric wave, the trade off between the onshore sediment flux induced by crest velocities and the offshore flux during the troughs is virtually zero. In contrast, waves with velocities that are different at crest phases compared to trough phases will generate a relatively stronger net transport than sinusoidal waves [Dibajnia and Watanabe, 1992; Dohmen-Janssen et al., 2002; Hsu and Hanes, 2004; Grasso et al., 2011b]. Shoaling waves nonlinearly generating super-harmonics exhibit differences in peak and trough velocities. Before wave breaking, the boundary layer is essentially forced by more or less pure skewed velocities that induce skewed bottom shear [Fuhrman et al., 2009]. A recent study by Suntoyo and

\footnotetext{
${ }^{1}$ LEGI UMR 5519, University of Grenoble, Grenoble, France.

${ }^{2}$ Now at Irstea, UR HHLY, Villeurbanne, France.

Corresponding author: C. Berni, Irstea, UR HHLY, 5 rue de la Doua, CS 70077, 69626 Villeurbanne Cedex, France. (celine.berni@irstea.fr)

(C)2013. American Geophysical Union. All Rights Reserved.

2169-9275/13/10.1002/jgrc.20125
}

Tanaka [2009] reporting experiments of oscillating air in a closed duct also shows, for a wide range of roughness ratios, that skewed free-stream velocity forcing produces skewed boundary shear stress.

[4] More surprisingly, a skewness in acceleration, called asymmetry, also produces an onshore net transport [Ruessink et al., 2011]. Asymmetry effects on sediment transport were considered to be irrelevant until laboratory experiments shed some light on this aspect [King, 1991]. Broken waves with steep pitched-forward fronts, also known as saw-tooth shape waves, are typical asymmetric waves found in the inner surf zone [Ruessink et al., 2012]. Evidence of on-shore sediment transport by asymmetric waves was reported by Elgar et al. [2001] who analyzed field data obtained at Duck, NC. They showed a strong correlation between the on-shore motion of the sand bar and the motion of the maximum velocity asymmetry location. More recently, laboratory experimental results in acceleration-skewed oscillatory flows by van $\operatorname{der} A$ et al. [2010] and Ruessink et al. [2011] show that more sediment is mobilized by the crest than the troughs, suggesting that a free-stream asymmetry possibly triggers a skewed shear stress in the boundary layer.

[5] Nielsen [1992] suggests the following physical explanation as to why asymmetry in velocity leads to skewed stresses. The wave boundary layer in the positive, rapidly accelerating half cycle has less time to grow than in the half cycle with less acceleration. This leads to larger (absolute) vertical gradients in flow velocity and, hence, larger shear stresses. This has been confirmed numerically by Fuhrman et al. [2009]. Using a k- $\omega$ numerical model to compute the boundary layer on a fixed bed, they show that a certain degree of wave asymmetry causes skewing of the bottom shear stress. Boundary layer measurements 
by van der $A$ et al. [2011] and Abreu et al. [2013] tend to confirm this behavior, although in U-tube devices that are known to produce flows with limited asymmetries compared to free surface waves in natural surf zones.

[6] Thus, both experimental and numerical results in the literature show that an asymmetric free-stream velocity can produce a skewed shear stress, indicating a transformation of the nonlinearities in the wave boundary layer. The purpose of this article is to understand how this transformation occurs. The study of the boundary layer structure of the flow and, more precisely, of the nonlinearities of the bottom velocity over a mobile bed is undertaken. This is of importance since recent work by Sparrow et al. [2012] shows that a permeable bed modifies the wave boundary layer dynamic.

[7] A theoretical framework to quantify the transformation of free-stream asymmetry to skewed bottom velocity was originally outlined in the work of Elgar [1987] who applied the concept of bi-spectrum to the analysis of velocity time series. This framework was supplemented by the work of Henderson et al. [2004]. They explain how the bottom velocity generated by an asymmetric free-stream velocity is skewed due to phase lead, the skewed shear stress being a direct consequence of a skewed near-bottom velocity. Indeed, assuming a frequency-independent phase shift in the boundary layer, the various Fourier components of the velocity will have different time shifts: the longer the wave, the larger the time shift. Fourier components of an asymmetric wave are piled up at the front of the wave, and their time shifting changes the shape of the orbital velocity from asymmetric to skewed. Building on this idea, the theoretical derivation by Henderson et al. [2004] yields a linear relationship between the near-bed skewness and the free stream asymmetry. On one hand, the phase difference between the free-stream and the near-bed flow is assumed to be frequency-independent. This is of course the case for laminar flows where phase lead is $45^{\circ}$ regardless of frequency. The fully turbulent flow simulations by Henderson et al. [2004], with a $k-\epsilon$ model forced by a particular set of freestream in situ velocity measurements, show that the phase lead is roughly constant $\left(25-30^{\circ}\right)$ over a wide range of frequencies. U-tube measurements at relatively high Reynolds numbers (between $10^{5}$ and $4 \times 10^{5}$ ) and for oscillation periods between $2 \mathrm{~s}$ and $4 \mathrm{~s}$ by Dick and Sleath [1991] over mobile beds give phase leads of roughly $15^{\circ}$ in the boundary layer. These three examples show a certain amount of scattering in phase shifts in oscillatory flows. A compilation by Jensen et al. [1989] shows that the phase lead of the bottom shear on fixed beds over the free-stream velocity varies gradually, decreasing from $45^{\circ}$ for laminar flows to less than $10^{\circ}$ for Reynolds numbers as high as $6 \times 10^{6}$. Phase lead is shown to be a decreasing function of $a / k_{s}$ where $a$ is the fluid particle motion amplitude and $k_{s}$ the Nikuradse roughness length scale.

[8] On the other hand, the derivation by Henderson et al. [2004] postulates a velocity amplitude attenuation from free-stream elevations to near-bottom elevations that is also frequency-independent. In the laminar case, this is not really the case as will be seen in the next section. Moreover, the same simulations by Henderson et al. [2004] for fully turbulent flows tend also to give a frequency-dependent attenuation.
[9] Although the simplified assumptions on attenuation and phase shift are not quite fulfilled, the $k-\epsilon$ model of Henderson et al. [2004] shows that near-bed velocity skewness and free-stream velocity asymmetry fall into a linear relationship with a high degree of correlation which gives an indication that this relationship seems to be more general than foreseen.

[10] Despite the considerable efforts made, there is a lack of experimental data, especially velocity measurements within the boundary layer under waves, over a movable bed, to better understand the role of asymmetry in sediment transport. This article presents profiles of velocity measurements within the boundary layer over a movable bed. Measurements are performed in the surf zone, where the wave asymmetry is of great importance. Nonlinearities, as quantified by the skewness and asymmetry of the velocity in the boundary layer, are analyzed in detail, and the transformation of asymmetry to skewness is studied. The theoretical background is first presented in the next section, the experimental set-up and results are then described in section 3, and implications are finally discussed in the last section.

\section{Theoretical Background}

[11] A nonlinear asymmetric wave is a combination of components of different frequencies that are phase-shifted in order to produce steep fronts with narrow peaks and troughs. Measures of the degree of nonlinearity are the skewness and the asymmetry [Elgar, 1987; Henderson et al., 2004]. The velocity skewness is defined by,

$$
S k(z)=\frac{\overline{(u(z, t)-\bar{u})^{3}}}{u_{\mathrm{rms}}^{3}(z)}
$$

and the velocity asymmetry is defined by,

$$
A s(z)=-\frac{\overline{\Im(\mathcal{H}(u))^{3}}}{u_{\mathrm{rms}}^{3}(z)},
$$

where $u(z, t)$ is the cross-shore horizontal velocity, with the overbar denoting a time-average over the studied interval, $\mathcal{H}(u)$ the Hilbert transform of $u, \mathfrak{s}$ the imaginary part, and $u_{\mathrm{rms}}(z)={\overline{(u(z, t)-\bar{u})^{2}}}^{1 / 2}$. The transformation of freestream velocity asymmetry to bottom velocity skewness in the boundary layer, described by Henderson et al. [2004], can be theoretically framed in more detail as follows.

[12] Consider the Fourier decomposition of the nonlinear cross-shore velocity:

$$
u(z, t)=\sum_{n=1}^{\infty}\left(A_{n}(z) e^{i \omega_{n} t}+\widehat{A}_{n}(z) e^{-i \omega_{n} t}\right),
$$

where $\widehat{A_{n}}$ is the complex conjugate of $A_{n}$ and $\omega_{n}=n \omega$, where $\omega$ is the fundamental angular frequency. The nonlinearities induce couplings between the different Fourier components. The coupling can be quantified using the autobispectrum $B$ [Elgar and Guza, 1985; Elgar, 1987] :

$$
B\left(\omega_{m}, \omega_{n}\right)=\left\langle A_{m} A_{n} \widehat{A_{m+n}}\right\rangle,
$$

where the angle brackets denote the ensemble average. The opposite of the imaginary part of the summation of $B$ components corresponds to the asymmetry $\left(A s^{*}\right)$ and the real 

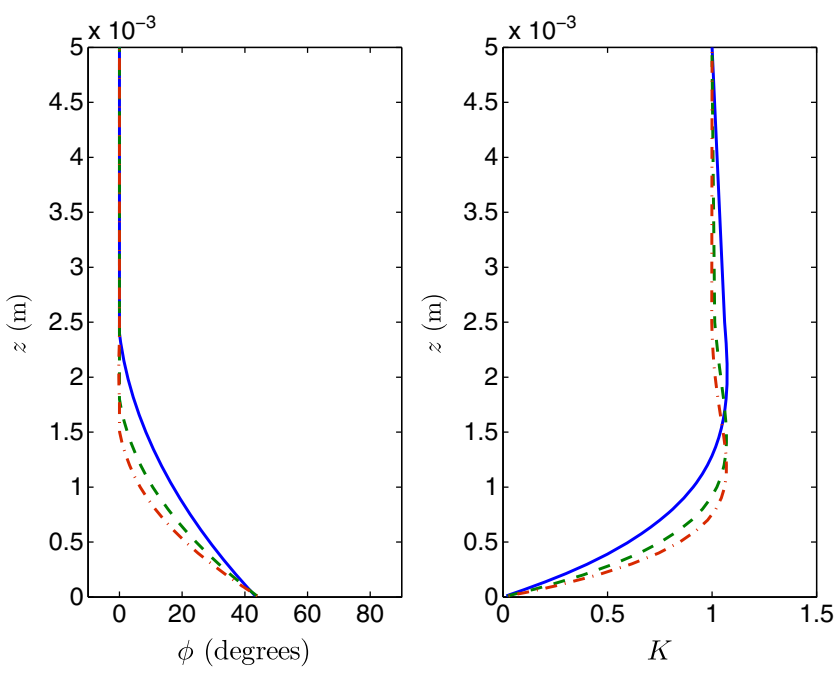

Figure 1. Velocity phase lead $\phi$ and attenuation factor $K$ of the first three Fourier components in the bed boundary layer computed with the Stokes solution (10): first (solid), second (dashed), and third (dashed-dotted) components for a fundamental period of $2.5 \mathrm{~s}$. The vertical axis is the altitude and $z=0$ stands for the position of the bed.

part to the skewness $\left(S k^{*}\right)$. The asymmetry and the skewness obtained by this method are not dimensionless and will be marked with a star hereinafter.

[13] If, moreover, it is assumed that a given component of the bottom velocity is equal to the same component of the free-stream velocity, attenuated and with a phase lead, the following relation stands between the Fourier coefficient of the free-stream velocity $\left(A_{n, \infty}\right.$ at $\left.z=z_{\infty}\right)$ and the bottom velocity $\left(A_{n, b}\right.$ at $\left.z=z_{b}\right)$ :

$$
A_{n, b}=A_{n, \infty} \times K_{b} e^{i \phi_{b}} .
$$

[14] Furthermore, if the attenuation coefficient $K_{b}$ and the phase lead $\phi_{b}$ are assumed to be independent of the angular frequency $\omega$, it is straightforward to show that the near bed auto-bispectrum is:

$$
\begin{aligned}
B\left(\omega_{m}, \omega_{n}, z_{b}\right) & =\left\langle A_{m, b} A_{n, b} \widehat{A_{m+n}, b}\right\rangle \\
& =\left\langle A_{m, \infty} A_{n, \infty} \widehat{A_{m+n}, \infty} K_{b}^{3} e^{i \phi_{b}}\right\rangle,
\end{aligned}
$$

and thus the model adapted from the work of Henderson et al. [2004] gives,

$$
S k_{b}^{*}=K_{b}^{3} \times\left(\cos \phi_{b} S k_{\infty}^{*}+\sin \phi_{b} A s_{\infty}^{*}\right),
$$

where $S k_{b}^{*}$ is the skewness at $z=z_{b}$ and $S k_{\infty}^{*}$ and $A s_{\infty}^{*}$ the free-stream skewness and asymmetry, respectively.

[15] The bottom velocity skewness therefore depends on the free-stream velocity skewness and the free-stream asymmetry. The attenuation factor $K_{b}$ is equal to $u_{\mathrm{rms}, b} / u_{\mathrm{rms}, \infty}$ so that:

$$
\frac{S k_{b}}{S k_{\infty}}=\frac{S k_{b}^{*}}{S k_{\infty}^{*}} \times \frac{1}{K_{b}^{3}},
$$

and the relation (7) can be written:

$$
\frac{S k_{b}}{S k_{\infty}}=\cos \phi_{b}+\sin \phi_{b} \frac{A s_{\infty}}{S k_{\infty}}
$$

which is a linear relationship between the nondimensional near-bottom skewness $S k_{b}$ and the nondimensional freestream asymmetry $A s_{\infty}$. As discussed in section 1, the linear relationship between asymmetry and skewness also seems to be retrieved in numerical models that do not assume a frequency-independent phase lead and attenuation. A simple model is used below to interrogate how general this result might be.

[16] As a start, it is known that at low Reynolds number, the velocity distribution in the wave boundary layer for a sinusoidal oscillatory flow can be described by the Stokes solution [Stokes, 1851]. For a given Fourier component of (3) with an angular frequency $\omega_{n}$, this reads,

$$
u_{n}(z, t)=a_{n} e^{i \omega_{n} t}\left(1-e^{-\beta_{n} z(1+i)}\right)
$$

where $\beta_{n}=\sqrt{\omega_{n} / 2 v}$ is the inverse of the viscous length scale, $v$ is the water viscosity, and $z$ is the vertical coordinate with $z=0$ at the bed. At small heights $z$ compared to $1 / \beta_{n}$, the limiting form of (10) is,

$$
u_{n}(z, t) \approx a_{n} \sqrt{2} \beta_{n} z e^{i\left(\omega_{n} t-\frac{1}{2} \beta_{n} z+\frac{\pi}{4}\right)} .
$$

[17] Figure 1 shows the vertical distribution of the phase lead and attenuation factor for the first three Fourier components of a $2.5 \mathrm{~s}$ wave. At $z=10^{-5} \mathrm{~m}$, the closest computed elevation above the bed, the phase lead $\phi$ and the attenuation factor $K$ increase with the Fourier component frequency. This Stokes solution will now be combined with a free-stream forcing typical of asymmetric waves.

[18] As used by many authors [Drake and Calantoni, 2001; Terrile et al., 2009; Abreu et al., 2010], free-stream asymmetric and skewed velocities can be described by the following finite sum of functions:

$$
u_{\infty}(t)=\sum_{n=1}^{N} \frac{1}{2^{n-1}} \cos \left(\omega_{n} t+(n-1) \zeta-\frac{\pi}{2}\right),
$$

where $\zeta$ is a measure of the degree of asymmetry. The component amplitude $A_{n}$ is simply $A_{n}=1 / 2^{n-1} \exp [i((n-1) \zeta-$ $\pi / 2)$ ]. A purely skewed wave is given by $\zeta=-\pi / 2$, a purely asymmetric wave by $\zeta=0$. Using (12), a set of 27

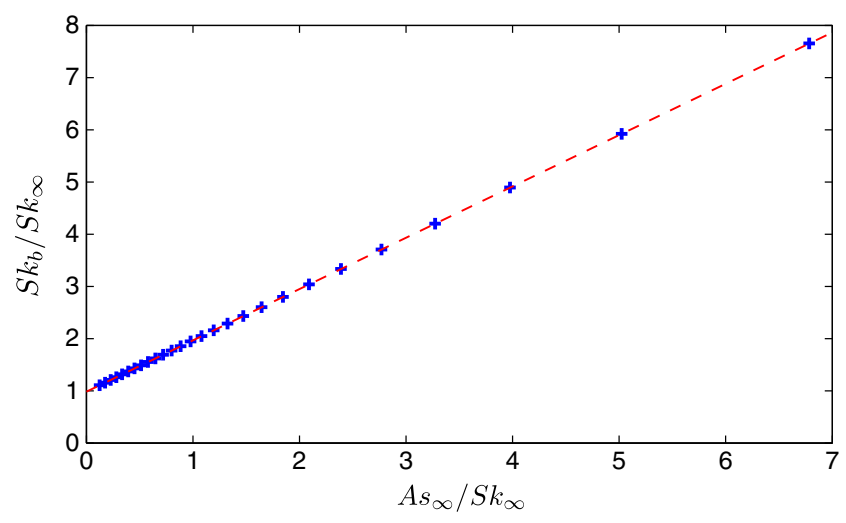

Figure 2. Near-bed to free-stream skewness ratio as a function of the free-stream asymmetry to skewness ratio with velocities computed by the phenomenological boundary layer model described by equations (10) and (12). Cross, data; dashed line, best linear approximation. 
a)

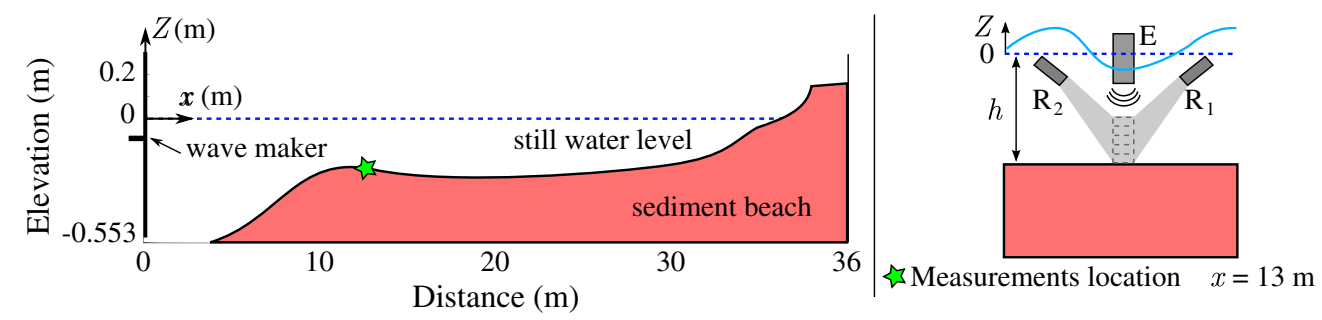

Figure 3. (a) Cross shore sketch of the LEGI wave flume set-up. The green star indicates the crossshore location of the ADVP. (b) Schematic diagram of the ADVP configuration with $E$ and $\left(R_{1}, R_{2}\right)$ being the piezoelectric emitter and receivers, respectively. The vertical column of rectangles below the emitter depict the measuring volumes.

free-stream velocity forcings is constructed by selecting 27 values of $\zeta$ in a range between 0.1 and 1.45 . The chosen angular frequency is $\omega_{1}=2 \pi / T$ with $T=2.5 \mathrm{~s}$. It is recognized that $N=8$ components is usually enough to retrieve the right wave shape.

[19] The next step is to assume that, for a given forcing (12), the boundary layer response is the linear superposition of the separate responses of the Stokes type (10) to each of the 8 components of the forcing (12). Consequently, each free-stream forcing generates a value of bottom $\left(S k_{b}\right)$ and free-stream $\left(S k_{\infty}\right)$ skewness and free-stream asymmetry $\left(A s_{\infty}\right)$. Ratios obtained from these 27 sets are plotted in Figure 2. A clear linear relation is observed between $S k_{b} / S k_{\infty}$ and $A s_{\infty} / S k_{\infty}$ even though the model is not based on a frequency independent attenuation factor $K_{b}$. Note that the simple relation (9) cannot be used here since the plot indicates that $\cos \phi_{b}$ and $\sin \phi_{b}$ should simultaneously be equal to unity. In the next section, the linear relationship between velocity skewness and asymmetry is confronted to experimental data.

\section{Experiments}

\subsection{Experimental Facility}

[20] The experiments were performed in a $36 \mathrm{~m}$ long, $0.55 \mathrm{~m}$ wide wave flume (Figure 3). The flume is filled with Polymethyl Methacrylate (also known as Plexiglas) sediment of low density $\left(1180 \mathrm{~kg} \mathrm{~m}^{-3}\right)$ forming a beach. The median diameter of the sediment is $d_{50}=0.64 \mathrm{~mm}$. The corresponding settling velocity is $21 \mathrm{~mm} \mathrm{~s}^{-1}$ [see Grasso et al., 2009, 2011a, for more details on the experimental facility]. The wave forcing is produced by a computercontrolled piston-type wave maker. There is neither wave absorption nor second-order correction on the wave maker motion.

[21] Capacitive wave gages are placed in the cross-shore direction of the beach to measure free-surface elevations. Beach profiles are recorded between wave series using an acoustic profiler mounted on a motorized trolley.

[22] Vertical profiles of the cross-shore velocity are measured at $x=13 \mathrm{~m}$ away from the wave maker with an acoustic Doppler velocity profiler (ADVP) [Hurther, 2001]. The three piezoelectric ceramics (one emitter and two receivers) are located just below the minimum water level at the wave troughs (Figure 3b). The emitted acoustic wave of carrier frequency $1 \mathrm{MHz}$ travels vertically downwards. At this fre- quency, the device also acting as a sonar can track the instantaneous bed level position (see Silva et al. [2009]; Hurther and Thorne, [2011]; Berni et al. [2012] for more details). The resolution on the vertical position for both bed level and velocity sampling volumes is $3 \mathrm{~mm}$. Depending on the water depth, 6 to 19 measures of the velocity are obtained. In the following, the free-stream velocity $u_{\infty}$ is defined as the cross-shore velocity measured at the elevation where the velocity amplitude is maximum. The near-bed velocity $u_{b}$ is defined as the velocity measured in the first sampling volume above the mean position of the still bed level, i.e., at an elevation $z_{b}$ between 0 and $3 \mathrm{~mm}$ above this level. The sampling frequency for the velocity, the bed level, and the free-surface elevation is $50 \mathrm{~Hz}$.

\subsection{Wave Conditions}

[23] The wave climate is a repetition of a specific wave sequence of duration $T_{s}=53 \mathrm{~s}$. It results from the concatenation of two bichromatic packets with a carrier wave period of $2 \mathrm{~s}$ and $2.5 \mathrm{~s}$, respectively (Figure 4). The target freesurface elevation $\eta_{i}$ for the bichromatic packet $i$ is written as follows:

$$
\eta_{i}(x, t)=A \cos \left(\omega_{i, 1} t-k_{i, 1} x\right)+A \cos \left(\omega_{i, 2} t-k_{i, 2} x\right),
$$

where $A=40 \mathrm{~mm}$ for both packets and $x$ is the cross-shore position. The angular frequencies for the packet with a wave period of $2 \mathrm{~s}$ are $\omega_{1,1}=3.0 \mathrm{rad} \mathrm{s}^{-1}$ and $\omega_{1,2}=3.3 \mathrm{rad} \mathrm{s}^{-1}$; for

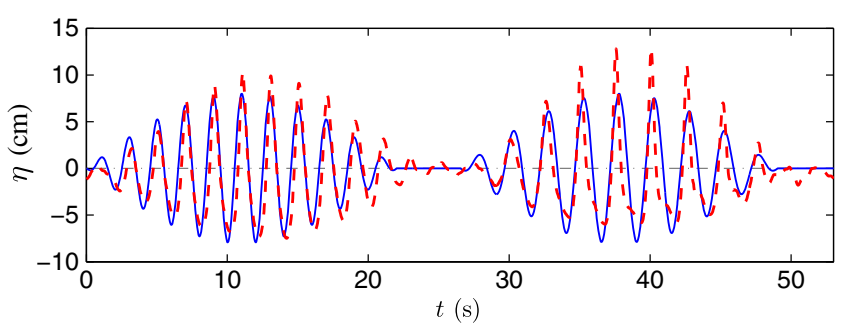

Figure 4. The $53 \mathrm{~s}$ wave sequence: first packet with $2 \mathrm{~s}$ carrier period, second packet with $2.5 \mathrm{~s}$ carrier period. Solid line, target free-surface displacement assigned to the wave maker; and dashed line, measurements with a capacitive wave gage at $x=2 \mathrm{~m}$. 

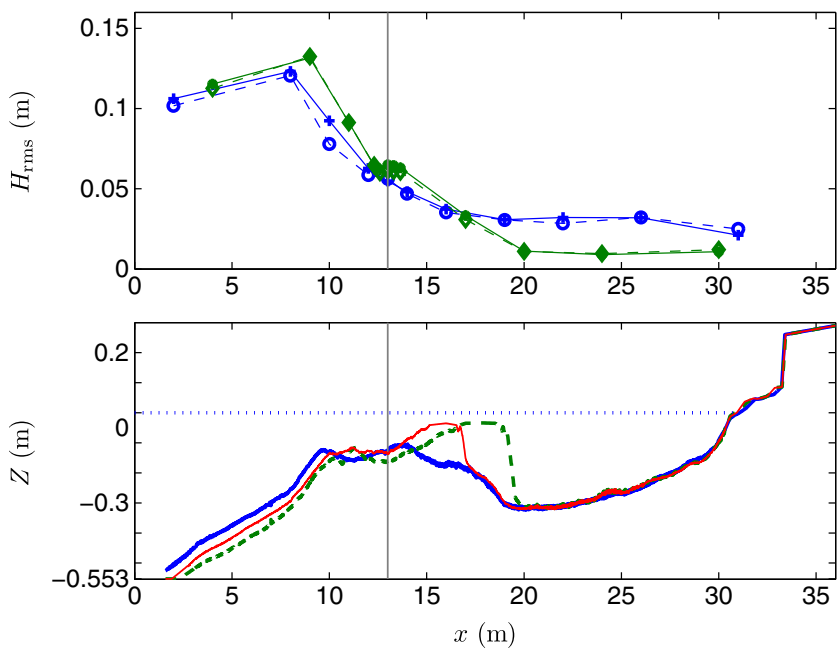

Figure 5. (top) Root mean square wave height for the experiment 1 (see Figure 12, cross, $T=2 \mathrm{~s}$; circle, $T=2.5 \mathrm{~s}$ ) and the experiment 42 (asterisk, $T=2 \mathrm{~s}$; diamond, $T=$ $2.5 \mathrm{~s}$ ). (bottom) Topography of the beach after the experiment 1 (bold solid line), the experiment 8 (thin solid line) and the experiment 42 (dashed line). $x=0$ is the mean position of the wave maker and $Z=0$ is the still free surface (horizontal dotted line). The vertical line indicates the measurement location.

the packet with a wave period of $2.5 \mathrm{~s}, \omega_{2,1}=2.4 \mathrm{rad} \mathrm{s}^{-1}$ and $\omega_{2,2}=2.7 \mathrm{rad} \mathrm{s}^{-1}$. The wave numbers $k_{i, j}$ are given by the dispersion relation:

$$
\omega_{i, j}^{2}=g k_{i, j} \tanh \left(k_{i, j} h_{0}\right),
$$

where $h_{0}$ is the water depth at the wave maker. The significant wave height at the wave maker is $0.16 \mathrm{~m}$ for both groups.

[24] The initial, intermediate (after 1150 wave sequences of $53 \mathrm{~s}$ ) and final (after 3150 wave sequences) beach profiles are plotted in Figure 5. During the experiments, a bar progressively formed and migrated onshore. The root mean square wave heights $H_{\mathrm{rms}}$ for the initial and final profiles are plotted in the top panel. The break point was stationary on the whole, at a distance of roughly $8 \mathrm{~m}$ from the wave maker. The surf zone extends from there up to the bar trough $(x \sim 20 \mathrm{~m})$. The measurements analyzed in this paper are all recorded within the surf zone at $x=13 \mathrm{~m}$.

\subsection{Boundary Layer Scaling}

[25] The scaling of this experimental facility for similar wave conditions has been studied in depth by Grasso et al., [2009, 2011a, 2011b]. The prototype is a non-cohesive sediment beach. A single horizontal and vertical length scale of 1/10 was chosen. Froude scaling then requires the velocity to be scaled as $1 / 3$ in the model. The overall beach morphodynamics was shown to be correctly reproduced by matching both dimensionless fall velocity (Rouse or Dean number) and Shields number. Table 1 summarizes the different parameters for a prototype and our model. The Reynolds number is smaller in the experiments than in nature but large enough for the flow to be turbulent. The Rouse numbers, or dimensionless settling velocities, are comparable. The Shields number is estimated by

$$
\theta=f_{w} \frac{u_{\mathrm{rms}}^{2}}{g(s-1) d_{50}},
$$

where $s$ is the relative density of the sediment ( $s=1.18$ in our experiment) and $f_{w}$ is the friction coefficient estimated according to Swart [1974] by:

$$
f_{w}=\exp \left[5.213\left(\frac{2.5 d_{50}}{a}\right)^{0.194}-5.977\right] \text {. }
$$

As shown in the work of Grasso et al. [2009], the Shields number is found to be similar in our experiment and in various prototypes. At our measurement location, $u_{\mathrm{rms}} \sim 0.14 \mathrm{~m} \mathrm{~s}^{-1}$ and the Shields number is 0.5 . This value corresponds to a transition regime between ripples and sheet flow dynamics. However, this estimate does not take into account the possible acceleration effects on the shear stress. For instance, Nielsen [2006] showed that a strong acceleration (typical of surf zone waves) can lead to higher Shields numbers. This is not taken into account in formulas such as (15). At certain phases of the wave, the Shields number in the experiment is higher and sheet flow develops.

[26] As the Shields number is similar to that found in nature, the sheet flow thickness and the ratio of roughness $k_{s}$ to median diameter are also similar. Indeed, the sheetflow thickness $\delta_{s}$ and the equivalent roughness length $k_{s}$

Table 1. Model—Prototype Comparison of Flow Parameters ${ }^{\mathrm{a}}$

\begin{tabular}{lcc}
\hline Parameters & Prototype & Model \\
\hline Velocity $u_{\mathrm{rms}}\left(\mathrm{m} \mathrm{s}^{-1}\right)$ & 0.5 & 0.14 \\
Wave period $T(\mathrm{~s})$ & 8 & 2.5 \\
Orbital excursion $a=\sqrt{2} u_{\mathrm{rmm}} T / 2 \pi(\mathrm{m})$ & 0.9 & $8 \cdot 10^{-2}$ \\
Reynolds number $R e=\sqrt{2} u_{\mathrm{rms}} a / v$ & $6 \cdot 10^{5}$ & $1.6 \cdot 10^{4}$ \\
Median diameter $d_{50}(\mathrm{~m})$ & $3 \cdot 10^{-4}$ & $6.4 \cdot 10^{-4}$ \\
Specific density $s$ & 2.65 & 1.19 \\
Friction factor $f_{w}$ & $9 \cdot 10^{-3}$ & $3 \cdot 10^{-2}$ \\
Shields number $\theta$ & 0.5 & 0.5 \\
Friction velocity $u^{*}=\sqrt{f_{w}} u_{\mathrm{rms}}\left(\mathrm{m} \mathrm{s}^{-1}\right)$ & $4.9 \cdot 10^{-2}$ & $2.4 \cdot 10^{-2}$ \\
Settling velocity $w_{s}\left(\mathrm{~m} \mathrm{~s}^{-1}\right)$ & $4.0 \cdot 10^{-2}$ & $2.1 \cdot 10^{-2}$ \\
Rouse number $R o u=w_{s} / \kappa u^{*}$ & 2.1 & 2.2 \\
Wave boundary layer Reynolds number $R e_{\mathrm{WBL}}$ & 212 & 127 \\
\hline
\end{tabular}

aPrototype data are typical of moderate wave conditions and sediment at Duck beach [e.g., Lippmann and Holman, 1990; Elgar et al., 2001] and stand within the range of parameters in Elfrink et al. [2006]. $\boldsymbol{\kappa}$ is the von Karman constant, $\kappa=0.4$ The sand settling velocity is computed using the formula of Ferguson and Church [2004]. 
a)

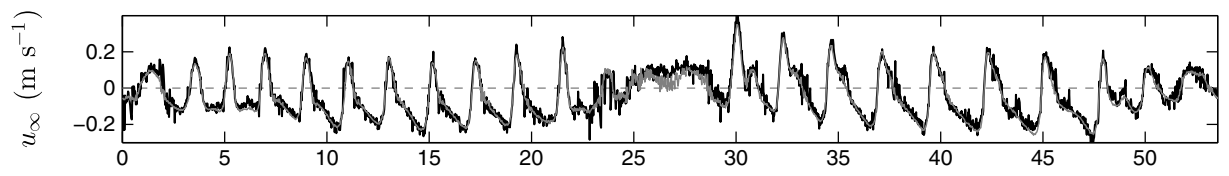

b)

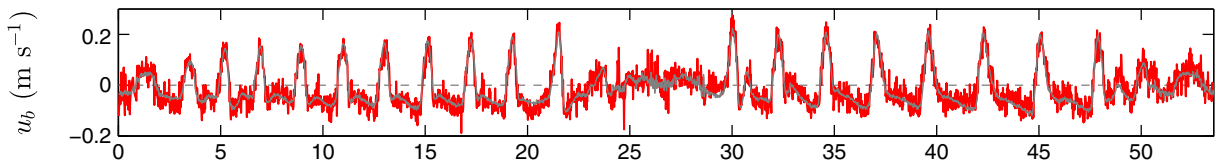

c)

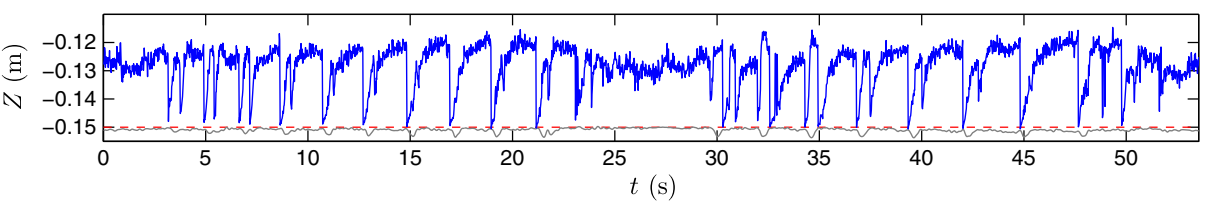

Figure 6. Examples of (a) instantaneous free-stream velocity and (b) instantaneous near-bed velocity time series together with the corresponding ensemble averages (gray lines). (c) Ensemble average of the estimated location of the top of the wave boundary layer (blue line) and ensemble average of the estimated bed position (gray line). The near-bed velocity $u_{b}$ is measured at $Z=-0.15 \mathrm{~m}$, indicated as a dashed line in Figure 6c. The processed signals are a record of the 28th experiment (Figure 12).

are estimated by the Wilson [1987, 1989] parameterizations given by,

$$
\begin{aligned}
& \delta_{s}=10 \theta d_{50}, \\
& k_{s}=5 \theta d_{50} .
\end{aligned}
$$

According to these equations, the sheet flow is about $3 \mathrm{~mm}$ thick and the equivalent roughness length about $2 \mathrm{~mm}$ in the present experiments.

[27] In this study, the focus is placed on the wave boundary layer dynamics for which, according to Dick and Sleath [1991], the free dimensionless parameters are the Shields number $\theta$ defined above, the ratio of orbital excursion to median diameter, and the boundary layer Reynolds number.

[28] The orbital excursion $a$ is estimated to be between 0.05 and $0.1 \mathrm{~m}$, values that are two orders of magnitude greater than the median diameter. Even though in nature $a / d_{50}$ can be much greater, the fluid particle displacements in the experiment at the bottom are still much greater than

a)

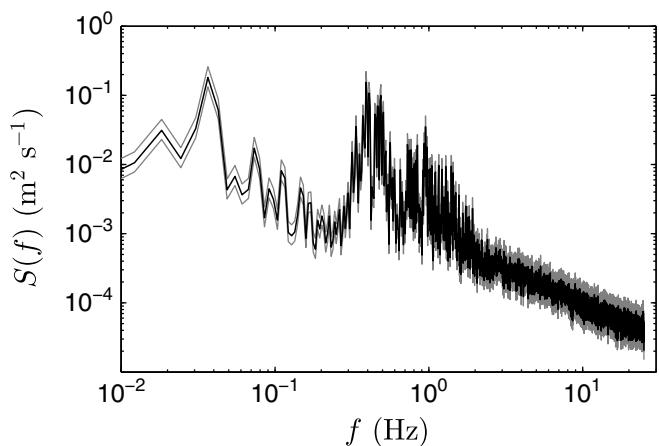

the grain diameter. Flow separations on the lee side of the grains still take place on most of the wave cycle.

[29] The boundary layer Reynolds number is the ratio of the grain size to the vertical viscous length scale:

$$
\operatorname{Re}_{\mathrm{WBL}}=\frac{\sqrt{2} u_{\mathrm{rms}} d_{50}}{v},
$$

where $v$ is the water kinematic viscosity. In our experiment, this number is around 120. Since the velocity in our experiment is three times smaller than the prototype to be modeled and the sediment is coarser, the boundary layer Reynolds number is then of the same order of magnitude as in the field. In both cases, these values ensure that the boundary layers are hydraulically rough.

[30] Given that these parameters characterize the wave boundary layer dynamics, the physical model presented in this article can be used to investigate the wave boundary layer over a sandy beach.

b)

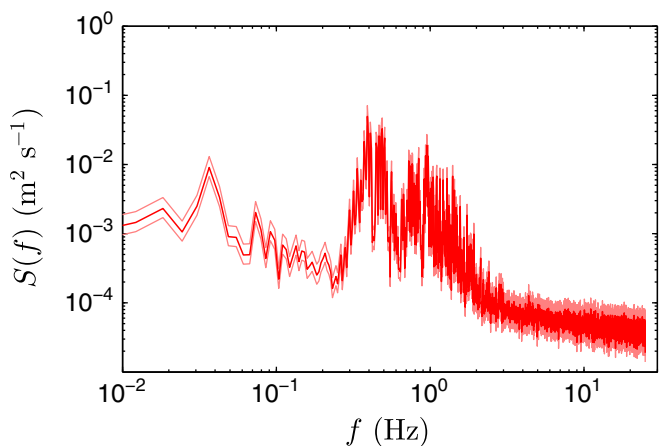

Figure 7. Power spectrum density of the instantaneous velocity computed over 45 min of measurement. (a) Free-stream velocity. (b) Near-bed velocity. Light lines represent the $95 \%$ confidence intervals. The processed signals are a record of the 28th experiment (Figure 12). 


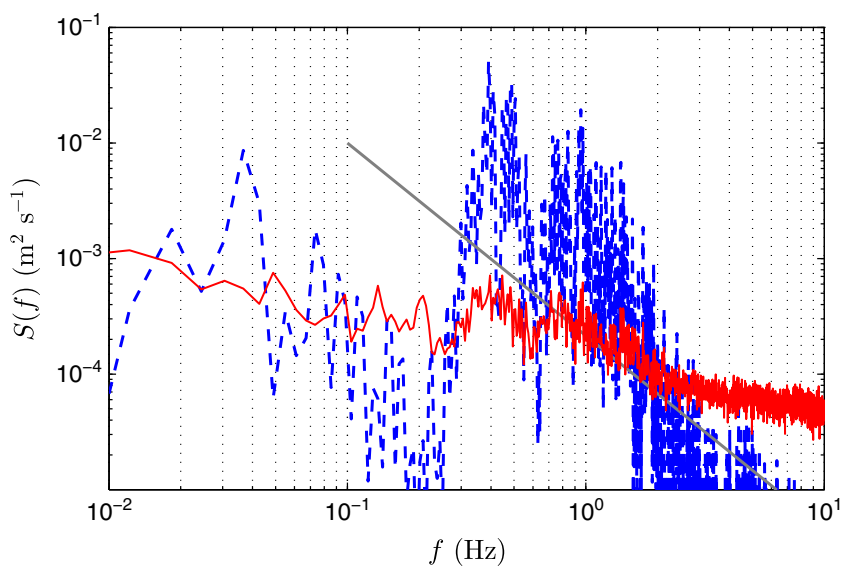

Figure 8. Power spectrum density of the ensemble averaged velocity (dashed line) and the turbulent/noise component (the solid line indicates the difference between the ensemble average and the instantaneous velocity). The gray line indicates the $-5 / 3$ slope. The processed signals are a record of the 28th experiment (Figure 12).

\subsection{Velocity Measurements}

[31] Examples of instantaneous velocities (within the 28th experiment) at both free-stream and near-bed elevations are given in Figures $6 \mathrm{a}$ and $6 \mathrm{~b}$. The two bichromatic groups can be distinguished, the first between $t=0 \mathrm{~s}$ and $t=26.5 \mathrm{~s}$, the second between $t=26.5 \mathrm{~s}$ and $t=53 \mathrm{~s}$. The mean bottom elevation over one wave sequence (of duration $T_{s}$ ) does not evolve significantly during a set of 30 to 50 sequences forming an experiment. The ensemble averaged velocities for this particular experiment are also plotted in Figures $6 \mathrm{a}$ and $6 \mathrm{~b}$. Most of the analysis will be made on ensemble average data. The ensemble average on $N$ realizations (between 30 and 50 wave sequences) is computed as:

$$
\langle u(t)\rangle=\frac{1}{N} \sum_{n=1}^{N} u\left(t+(n-1) T_{s}\right),
$$

where $T_{s}$ is the duration of the sequence.

[32] The ensemble average of the estimated location of the top of the wave bottom boundary layer, taken as the elevation where $u(Z)$ is maximum and has the same sign as $u_{b}$, is plotted in Figure $6 \mathrm{c}$, along with the ensemble averaged bed elevation. The boundary layer is building up after each flow reversal to reach a maximum thickness of about 20 to $30 \mathrm{~mm}$ just before the next flow reversal. The boundary layer under maximum negative flow is thicker than under maximum positive flow because it has more time to grow during the trough phases. This difference in thickness clearly increases with increasing velocity asymmetry, as can be seen by comparing the waves at the beginning of the first group to that in the middle of the same group for instance. This behavior has been suggested to be a main cause for larger shear stresses under wave crests and positive net transport for asymmetric flows [Nielsen, 1992; Suntoyo et al., 2008; Ruessink et al., 2011]. An erosion of the bed is detected at each wave crest. The maximum detected erosion within the sequence is approximately $3 \mathrm{~mm}$. This value is consistent with the estimate of the mean sheet-flow thickness obtained from equation (17). For this experiment, the near bed velocity $u_{b}$ is measured just above the mean bed elevation, at $Z=-0.15 \mathrm{~m}$.

[33] The density power spectrum of both $u_{\infty}$ and $u_{b}$ velocities are computed on 50 successive wave sequences (i.e., about 45-minute signals) and presented in Figure 7. They have similar shapes and both exhibit a peak at $1 / 26.5 \mathrm{~Hz}$ which corresponds to the length of each bichromatic wave packet. The first two eigenmodes of the wave seiching are computed using a finite difference method for the linearized nonlinear shallow water equations as in Kirby et al. [2006]. The eigenmodes have a maximum amplitude at about $1 / 48 \mathrm{~Hz}$ and $1 / 20 \mathrm{~Hz}$ respectively, values that slightly depend on the beach profiles. The frequency components of the bichromatics are chosen so as to avoid any resonance mechanism of the seiching modes. The four highest peaks around $0.4 \mathrm{~Hz}$ and $0.5 \mathrm{~Hz}$ correspond to the two pairs of frequencies making up the two bichromatic packets. The frequency peaks in the 0.6 to $2 \mathrm{~Hz}$ range are harmonics of these four basic frequencies. The large number of super-harmonics reflects a high degree of nonlinearity in the surf zone.

[34] Ensemble average velocity can be subtracted from the instantaneous velocity. The resulting difference is a signal that includes turbulence and noise. The spectral signature of each contribution is given in Figure 8. The power spectrum density of the ensemble average has a cut-off

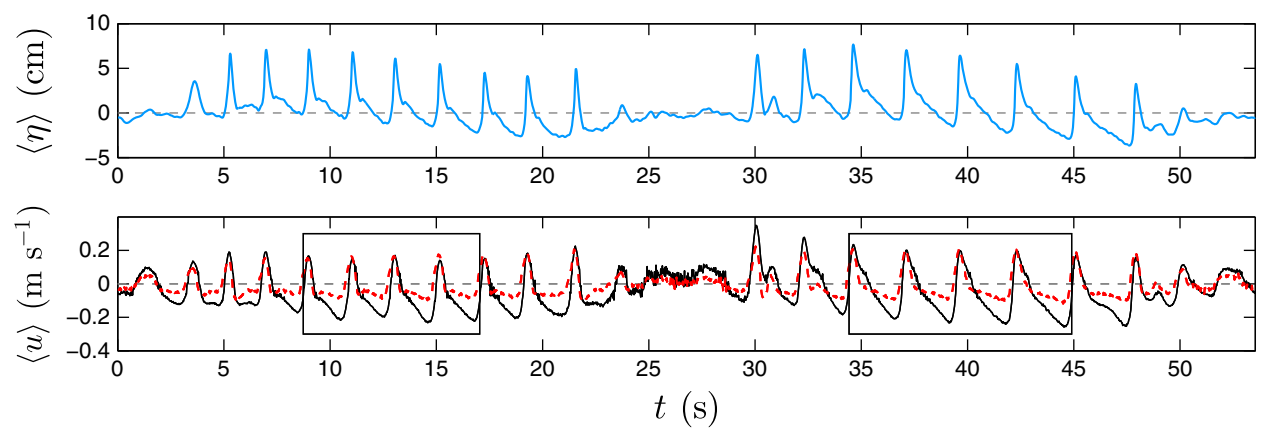

Figure 9. Examples of ensemble average time series of the (top) water free-surface elevation $\langle\eta(t)\rangle$, of the (bottom, solid line) free-stream velocity $\left\langle u_{\infty}\right\rangle$, and of the (bottom, dashed line) near-bed velocity $\left\langle u_{b}\right\rangle$ for the $53 \mathrm{~s}$ wave sequence defined by (13). The first wave packet has a peak period of $2 \mathrm{~s}$, the second, a period of $2.5 \mathrm{~s}$. The plotted signals correspond to the 28 th experiment of Figure 12 . The black box gives the analyzed portion of the signal for both forcings. 

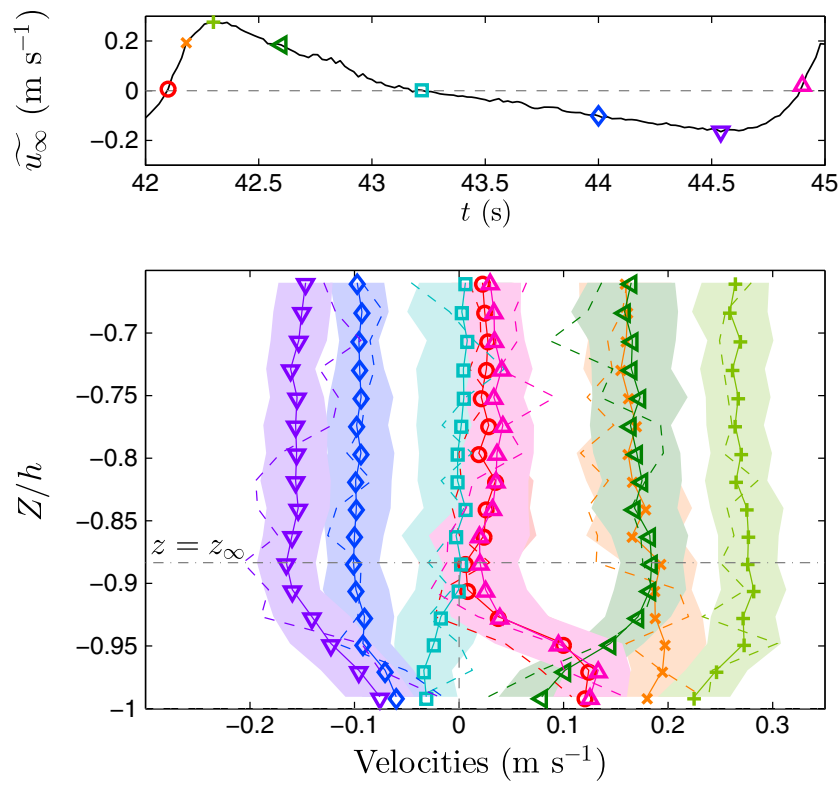

Figure 10. (top) Detail of the time series of the orbital free-stream velocity $\widetilde{u}_{\infty}$ corresponding to the experiment plotted in Figure 9. (bottom) Orbital velocity $\widetilde{u}$ profiles at the specific phases as marked on the top plot; dashed lines are high-pass filtered instantaneous velocity $\left(u-u_{\mathrm{lf}}\right)$ profiles, and shading indicates standard deviation around each orbital profile. The vertical axis is the dimensionless elevation; $Z / h=-1$ stands for the mean position of the bed; $Z / h=0$ for the still free-surface elevation. The water depth is $h=150 \mathrm{~mm}$ at the measuring location (28th experiment, Figure 12).

of around $2 \mathrm{~Hz}$. Below this cut-off, the turbulence/noise contribution is 10 to 100 times smaller in energy than that of the wave motion. Moreover, the turbulence/noise contribution has a slope of $-5 / 3$ in the $0.7 \mathrm{~Hz}$ to $2 \mathrm{~Hz}$ frequency range which is characteristic of turbulence. Smaller turbulent scales up to $25 \mathrm{~Hz}$ (Nyquist frequency) are probably not resolved due to the spatial resolution of $3 \mathrm{~mm}$. The ensemble averaging can therefore be relied upon to separate the wave related mean motion from the turbulence/noise contribution. The turbulence will not be analyzed further in this article.

[35] For all the experiments (41 groups of at least 30 sequences), dimensionless skewness and asymmetry were computed at the free-stream level $\left(z=z_{\infty}\right)$, the near-bed level $\left(z=z_{b}\right)$, and at $\left(z=z_{b}+p\right)$ above the near-bed elevation with $p \approx 3 \mathrm{~mm}$.

\subsection{Results}

[36] Time series of the ensemble average of the freesurface elevation, the free-stream and the near-bed velocities at the measurement location are shown in Figure 9. These data correspond to one representative example among the whole set of 41 experiments. The shape of the waves is typical of the surf zone waves, with pinched crests, long troughs, and pitched-forward waves. As expected in shallow water, the free-stream velocity and the free-surface elevation have similar shapes with pitched forward fronts.
[37] In contrast, the bottom velocity in Figure 9 is highly skewed. Note that the bottom velocity and the free-stream velocity at each crest are almost of the same value while the near-bed trough velocity is more than $50 \%$ smaller than its counterpart in the free-stream velocity.

[38] This is also illustrated with vertical profiles of orbital velocities at different phases of a single wave in Figure 10. The orbital velocity $\widetilde{u}$ is defined here as the difference between the ensemble averaged velocity $\langle u\rangle$ and the lowfrequency components $u_{\mathrm{ff}}$ (with a cut-off frequency of $3 / 5 \times$ $0.4 \mathrm{~Hz}$ ). These velocity profiles display greater absolute bottom velocities during the crest than during the trough. Examples of high-pass filtered instantaneous velocity $\left(u-u_{\text {lf }}\right)$ profiles are also plotted in the same figure, along with shadings which bounds are computed as the standard deviation of $\left(u-u_{\mathrm{lf}}\right)$ over the 45 realizations of the same experiment. The consistency of these different profiles further supports the relevance of the velocity decomposition and the limited impact of the beach evolution within each experiment.

[39] For this specific, not especially energetic, wave climate, the mobile bed layer is moderately thick $(\sim 3 \mathrm{~mm}$, see previous section). The first ADVP measurement volume, being above the bed at rest, is either above the sheet-flow or in the upper part of it during the wave sequence. Thus the concentration is low enough to measure reliable nearbed fluid velocities since the slippage between particles and fluid at this elevation is known to be small [Dick and Sleath, 1991]. The consistency of the velocity profiles (Figure 10) supports this conclusion. In particular, a phase lead of the near-bed velocity is observed at each flow reversal, which is characteristic of the wave boundary layer. Moreover, the vertical profiles of the root mean square velocities are shown in Figure 11 for both bichromatic packets. As found by Dick and Sleath [1991], the rms velocity follows a log law within the boundary layer. The equivalent roughness scale

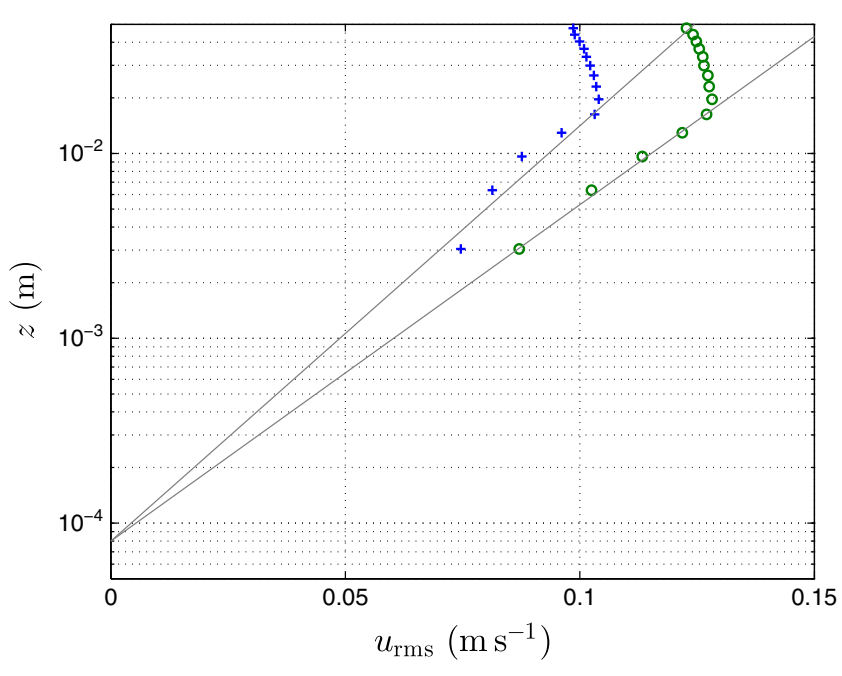

Figure 11. Root mean square of the ensemble averaged velocity profiles. Crosses and circles relate respectively to the first and second analyzed portions specified in Figure 9. Cross, $T=2 \mathrm{~s}$; circle, $T=2.5 \mathrm{~s}$ (8th experiment, Figure 12). The vertical axis is the elevation above the bed. 
a)

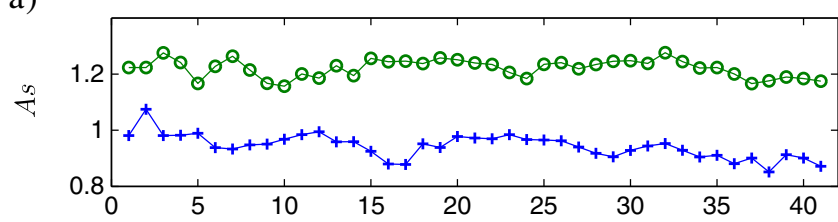

b)

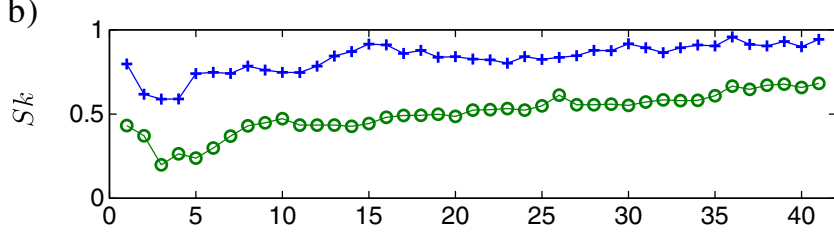

c)

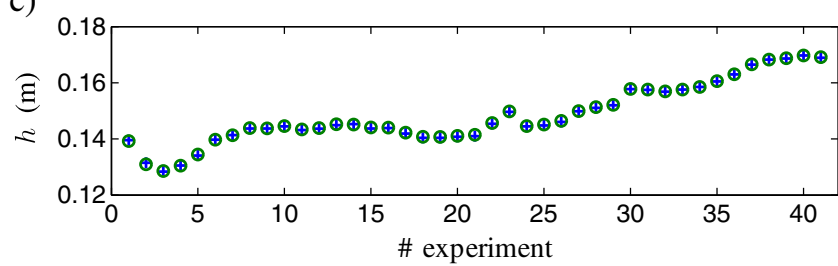

Figure 12. (a) Asymmetry and (b) skewness of the ensemble averaged free-stream velocity for the 41 experiments. (c) Mean water depth. Crosses and circles relate respectively to the first and second analyzed portions specified in Figure 9. Cross, $T=2 \mathrm{~s}$; circle, $T=2.5 \mathrm{~s}$.

determined in this manner is about $2 \mathrm{~mm}$, in agreement with the estimation given in section 3.2.

[40] In the following analysis of nonlinearities, it was decided to study only the four middle waves of each group, identified by a box on the time series in Figure 9. The two time bounds of the box are times with zero up-crossing of the free-stream orbital velocity. Both intervals are analyzed and studied separately as they correspond to two different wave periods and therefore to two different forcings. Both the ensemble average velocity and the orbital velocity (i.e., including or not the low-frequency components) are analyzed and a similar trend is obtained. Indeed, over the small intervals studied, the velocities inferred from the infragravity waves are nearly constant, and as the mean velocity in the skewness computation is removed, the behavior is very similar.

[41] As the beach shape evolves during the 41 experiments, a wide range of values for the free-stream skewness and high values of the asymmetry are obtained. Figure 12 presents these values throughout the 41 experiments for both periods. For both periods, the skewness is gradually increasing during the 41 experiments. This is related to the increase in water depth, as a result of the slow overall onshore bar migration shown in Figure 5. In our experiments, waves of $2.5 \mathrm{~s}$ period are more asymmetric and less skewed than the waves of $2 \mathrm{~s}$ period.

[42] As an example, for experiment number 28 of these 41 experiments (Figure 12), the vertical profiles of the root-mean-square velocity $u_{\mathrm{rms}}$, the mean velocity $\bar{u}$, the skewness, and the asymmetry are plotted in Figure 13 for both bichromatic packets. The root mean square value of the velocity (Figure 13a) decreases down to the bed in the wave boundary layer. The mean velocity $\bar{u}$ (Figure 13b) is negative in the upper part of the profile, indicating the presence of an undertow. It decreases deeper down in the boundary layer. The profile surprisingly concaves downwards but this is probably due to the mobile bed which is also what O'Donoghue and Wright [2004] found. In addition, measurements by Sparrow et al. [2012] over both impermeable and permeable beds also suggest that permeability can induce an inflection in the mean velocity profiles. Both forcings at different periods show similar behavior although the free-stream values of the rms and mean velocity are different. Figure $13 \mathrm{c}$ shows a plot of the non-dimensional skewness $S k$ of the velocity. This skewness increases down to the bed while the asymmetry decreases as shown in Figure 13d. The increase in skewness is greater for the $2.5 \mathrm{~s}$ wave period which presents a greater free-stream asymmetry.

[43] If the 41 experiments are now considered again, the ratios appearing in equation (9) are plotted in Figure 14a for $z=z_{b}$. A clear linear relation (correlation coefficient of 0.99 ) is shown between these two ratios regardless of the forcing. This linear relationship holds with or without filtering the low-frequency components. By matching the slope and the y-intercept to $\sin \phi$ and $\cos \phi$ as suggested by (9), two close values of $\phi: 44$ and $42^{\circ}$, respectively, are obtained at $z=z_{b}$. The same analysis is carried out on each individual sequence, the results of which are shown in Figure 14b. The scatter of the data is wider but the overall linear trend is found.

[44] The same ratios are plotted in Figure 14c at an elevation $z=z_{b}+p$ just above $z_{b}$. Again, a clear linear relation (correlation coefficient of 0.95 ) is shown but with a gentler slope. The two values for $\phi$ computed with (9) are 30 and $19^{\circ}$. The discrepancy is greater than for $z_{b}$ but the overall decrease in the $\phi$ value is consistent with the fact that the phase lead decreases with increasing distance from the bed.
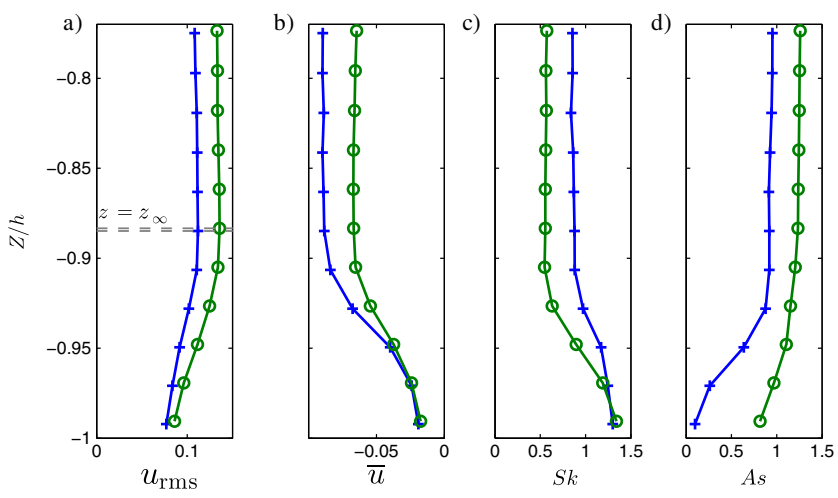

Figure 13. Examples of (a) root-mean-square velocity $u_{\text {rms }}$, (b) mean velocity $\bar{u}$, (c) skewness $S k$, and (d) asymmetry $A s$ profiles computed from ensemble averaged velocities, for the two intervals studied, as specified in Figure 9, corresponding to the two wave forcings: cross, $T=2 \mathrm{~s}$; circle, $T=2.5 \mathrm{~s}$. The vertical axis is the dimensionless elevation, $Z / h=-1$ stands for the mean position of the bed, $Z / h=0$ for the still free-surface elevation, with the water depth $h=150 \mathrm{~mm}$ at the measuring location (28th experiment, Figure 12). 

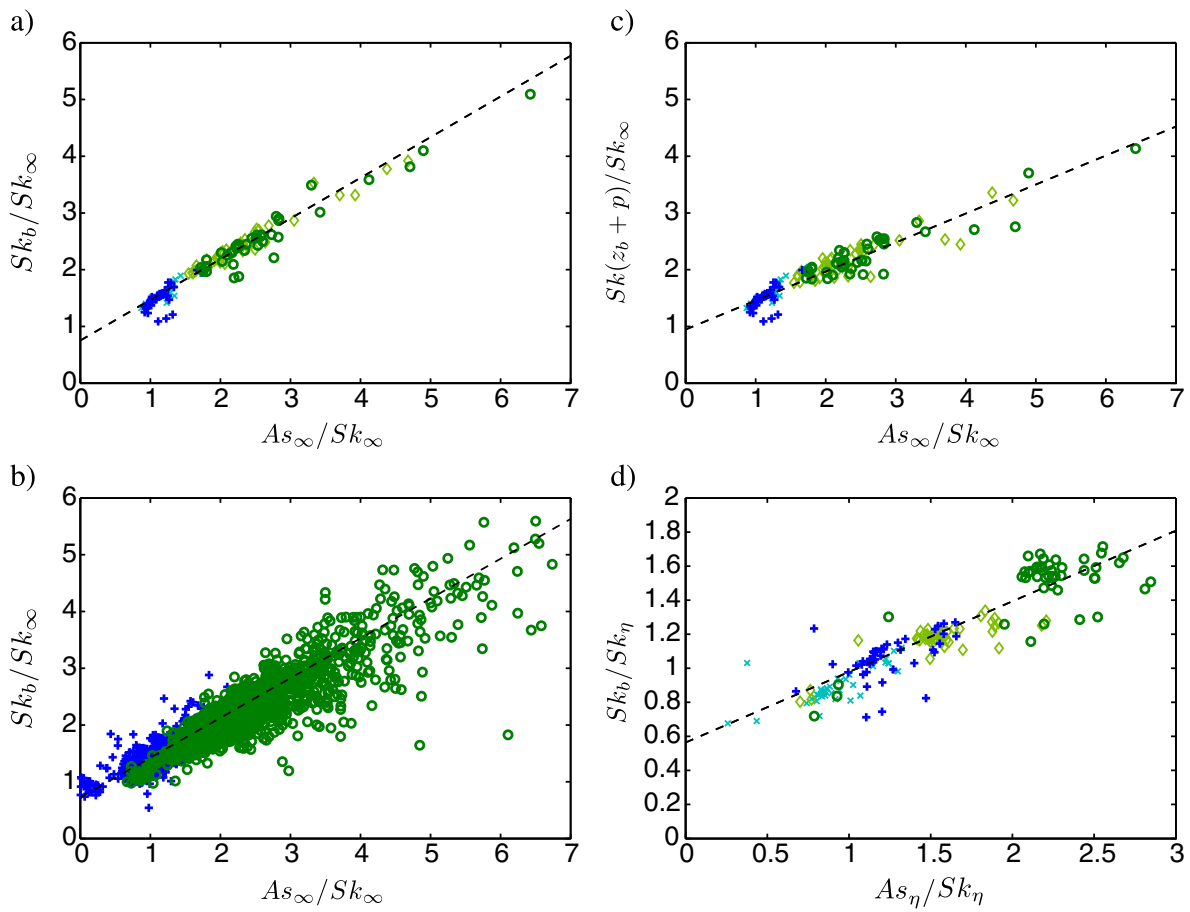

Figure 14. Near-bed to free-stream skewness ratio as a function of the free-stream asymmetry to skewness ratio for (a) the ensemble average velocity at $z=z_{b}$; (b) the instantaneous velocity at $z=z_{b}$; and (c) the ensemble average velocity at $z=z_{b}+p$. (d) Ratio of the near-bed velocity skewness (at $z=z_{b}$ ) to the free-surface elevation skewness as a function of the free-surface elevation asymmetry to skewness ratio for the ensemble average signals. $T=2 \mathrm{~s}$ (cross, times symbol) and $T=2.5 \mathrm{~s}$ (circle, diamond); from signals without the low-frequency components (times symbol, diamond), from signals including the low-frequency components (cross, circle), and best linear approximation (dashed line).

[45] Michallet et al. [2011] showed that free-stream velocity reconstruction from free surface elevation signals involves errors that are detrimental to estimate velocity skewness and asymmetry . Nevertheless, we replace in (9) the free-stream velocity skewness and asymmetry by the free-surface elevation skewness and asymmetry for computing the ratios that are plotted in Figure 14d. The linear relationship still holds, despite smaller correlation coefficients $(0.89$ for the full ensemble average signals including the low-frequency components, and 0.91 for the orbital signals) compared to that computed with the velocity only.

[46] An understanding of the detailed structure of the boundary layer velocity profile can be obtained by harmonically analyzing the flow at each elevation and plotting the vertical profile of the Fourier component amplitudes and phases. This is done for each time box defined in Figure 9, for the first three Fourier components. Profiles of the phase lead $\phi$ and the attenuation $K$ within the boundary layer are given in Figure 15 for both wave periods. The same experiment as for Figure 13 is taken here as an example. The higher level plotted is the free-stream elevation in dimensionless coordinates. Progressing down to the bed, the phase lead increases as the attenuation factor decreases. Near the bed, the phase lead reaches a value of $30^{\circ}$ for the first two Fourier components, and 20 to $25^{\circ}$ for the third Fourier component. All these values are in the same range as those determined by using the linear relation (9). The discrepancies between the Fourier analysis and (9) are deemed to be due to errors in the phase estimation but also to the strong hypothesis that the attenuation factor in (5) does not depend on the frequency of the free-stream forcing.

[47] This analysis was performed for the 41 experiments. The average phase values and standard deviations obtained are summarized in Table 2. The near-bed phase lead of the

Table 2. Phase lead $\phi$ of the boundary layer phase-averaged velocities at elevations $z_{b}$ and $z_{b}+p$ with regard to the free-stream phase-averaged velocity for the first three Fourier components

\begin{tabular}{|c|c|c|c|c|c|c|c|c|c|c|c|c|}
\hline \multirow[b]{3}{*}{ Fourier components } & \multicolumn{6}{|c|}{$T=2 \mathrm{~s}$} & \multicolumn{6}{|c|}{$T=2.5 \mathrm{~s}$} \\
\hline & \multicolumn{3}{|c|}{$z_{b}$} & \multicolumn{3}{|c|}{$z_{b}+p$} & \multicolumn{3}{|c|}{$z_{b}$} & \multicolumn{3}{|c|}{$z_{b}+p$} \\
\hline & $1 \mathrm{st}$ & $2 \mathrm{nd}$ & $3 \mathrm{rd}$ & $1 \mathrm{st}$ & $2 \mathrm{nd}$ & $3 \mathrm{rd}$ & $1 \mathrm{st}$ & $2 \mathrm{nd}$ & $3 r d$ & $1 \mathrm{st}$ & $2 \mathrm{nd}$ & $3 \mathrm{rd}$ \\
\hline$m_{\phi}$ & 32 & 33 & 26 & 28 & 25 & 21 & 29 & 29 & 20 & 25 & 21 & 15 \\
\hline$\sigma_{\phi}$ & 3 & 4 & 5 & 3 & 4 & 4 & 2 & 4 & 4 & 3 & 4 & 3 \\
\hline
\end{tabular}

Average value $m_{\phi}$ and standard deviation $\sigma_{\phi}$ 

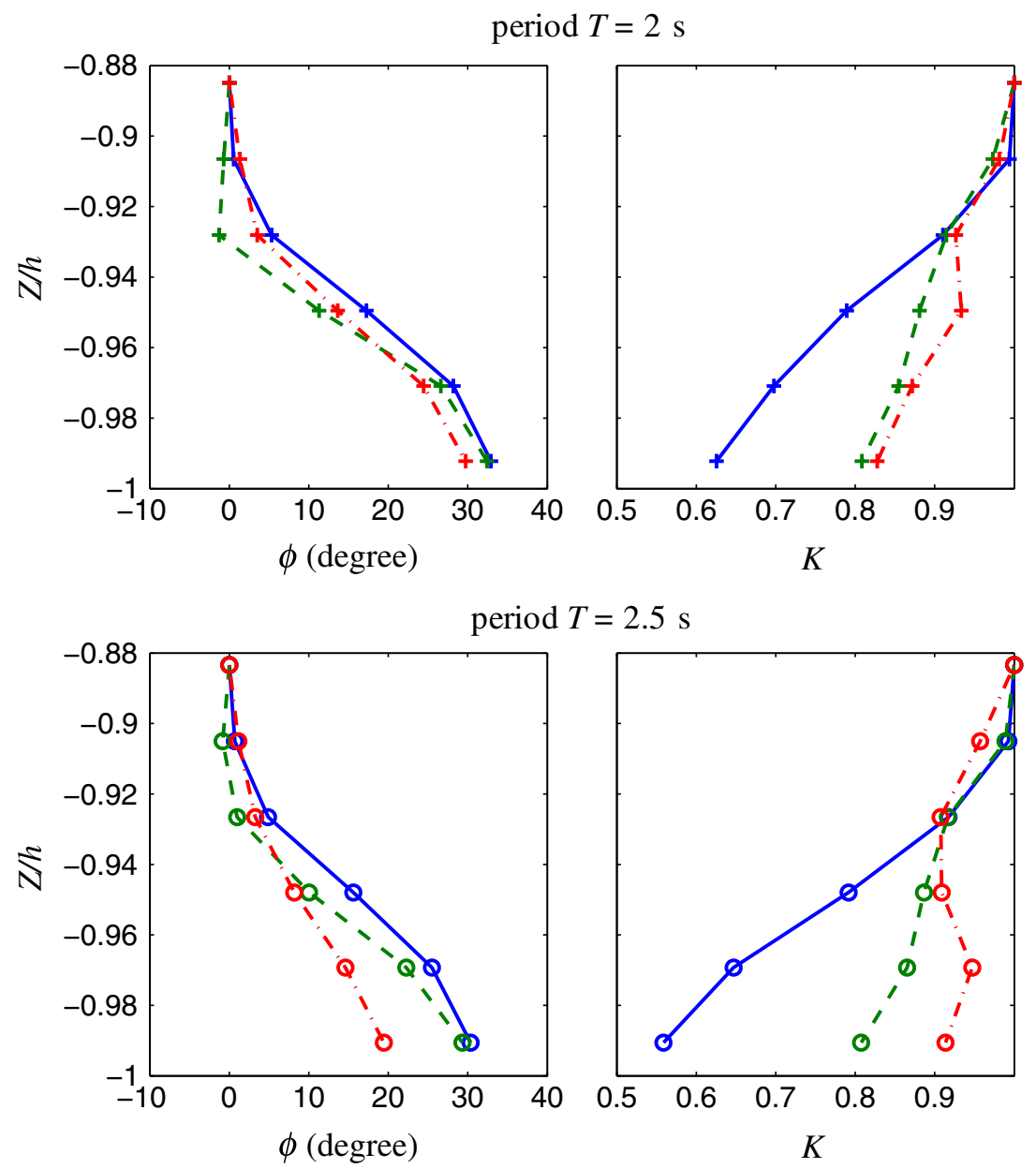

Figure 15. Profiles of the phase lead $\phi$ and the attenuation factor $K$ for the first three Fourier components of the ensemble average velocity. Values deduced from Fourier analysis of the velocity: first (solid), second (dashed), and third (dashed-dotted) components, for the two wave forcings: cross, $T=2 \mathrm{~s}$; circle, $T=2.5 \mathrm{~s}$. The vertical axis is the dimensionless altitude, $Z / h=-1$ stands for the mean position of the bed, $Z / h=0$ for the still free-surface elevation, with the water depth $h=150 \mathrm{~mm}$ at the measuring location (28th experiment, Figure 12).

first two components is similar, but different from the phase lead of the third component. The phase lead at $z=z_{b}+p$ is significantly lower, and differences are apparent between the first two components. The average value of the attenuation factor also depends on which component is considered. It is of about 0.6 to 0.7 for the first component and 0.8 to 0.9 for the second and the third components at both elevations: $z_{b}$ or $z_{b}+p$. These values might seem high, but it should be noted that the experiments involve a mobile bed to the extent that the erosion, by lowering the still bed level, is conducive to strong velocities at the mean/initial elevation of the bed $z=0$.

\section{Discussion and Conclusions}

[48] Measurements of ensemble averaged velocities within the bottom boundary layer under waves were analyzed. A robust linear relation is found between the free-stream velocity asymmetry and the bottom velocity skewness. This relation depends on the phase lead between the components of the near-bed velocity and the freestream velocity. According to relation (9) between the free-stream velocity asymmetry and the bottom (first sampling volume) velocity skewness, this phase lead is estimated to be approximately $40^{\circ}$. A Fourier analysis gives a mean value of $30^{\circ}$ at this elevation. The causes for this difference were investigated using an oscillating laminar-bed boundary layer model. It was established that the variations in the attenuation factor with respect to the frequency can be responsible for variations in the slope of the linear relation (9). Nevertheless, these experimental values are consistent with the synthesis given by van $\operatorname{der} A$ et al. [2011] showing how this phase lead varies with the ratio $a / k_{s}$. Using the equivalent roughness length $k_{s}$ given by (18), our experimental data of $a / k_{s}$ is in the 38 to 50 range. From the data of van der A et al., [2011, Figure 6], the phase lead for our range of $a / k_{s}$ falls to a value of around $30^{\circ}$.

[49] As the phase lead increases (toward $45^{\circ}$ ), the transfer of free-stream asymmetry to bottom skewness increases. This explains why an asymmetric velocity can lead to a skewed shear stress. Several articles have suggested a transfer from free-stream asymmetry to skewed shear stress, such as the experiments presented by Henriquez et al. [2010] or 
a)
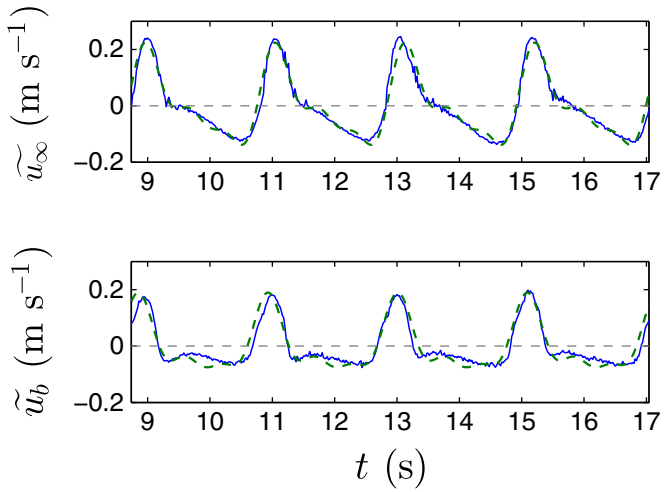

b)
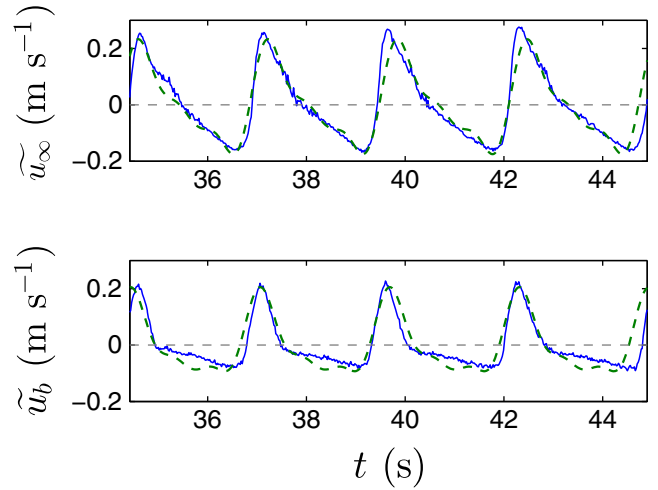

Figure 16. Example of time series of (top) free-stream and (bottom) near-bed orbital velocities for the two wave forcings: (a) $T=2 \mathrm{~s}$; (b) $T=2.5 \mathrm{~s}$. The solid lines correspond to the ADVP measurements at both elevations. (top) The dashed line is the reconstruction of the free-stream orbital velocity with the first three Fourier components only. (bottom) The dashed line corresponds to the near-bed orbital velocity computed applying a constant phase lead of $40^{\circ}$ and a constant attenuation coefficient of 0.8 to the first three Fourier components of the free-stream velocity (28th experiment, Figure 12).

the boundary layer model of Zhang et al. [2011]. In the present context, further investigations would be required for estimating the bed shear stress. Bed shear stress estimation under strongly accelerated flows with a classical method, such as the log-fit method for instance, is far from being straightforward. In particular, O'Donoghue et al. [2010] have shown that under a bore front, the shear stress measured with a shear plate is maximum but cannot be evaluated with the log-fit method.

[50] The new set of experiments presented in this article confirms the theory of Henderson et al. [2004] applied to the boundary layer and offers a new perspective for evaluating bottom velocity skewness from free-stream velocity measurements. Furthermore, the present analysis can provide a way of estimating the bottom velocity from the free-stream velocity. By Fourier analysis, the amplitude and the phase of the first three Fourier components of the free-stream velocity are computed. The top panel in Figure 16 shows that three components are sufficient to capture most of the wave shape. The near-bed velocity is computed by assigning a phase lead of $40^{\circ}$ and a constant attenuation of 0.8 to these three experimental components. In the second panel of Figure 16, the measured near-bed velocity is seen to match in a satisfactory way the computed near-bed velocity.

[51] This method offers a simple way of computing nearbed velocities and one could consider combining it with phase resolving wave models such as Boussinesq models, as an alternative approach to that of Briganti et al. [2011] for instance. Boussinesq type equations [e.g., Bonneton et al., 2011, and references therein] provide the nonlinear wave transformation on irregular bathymetries both in the shoaling zone and the inner surf zone, and nonlinear parameters such as $S k$ and $A s$ can be easily computed. Boussinesq type models can accurately compute the undertow compensating flow due to the wave roller and the Stokes drift, but they of course do not supply any information on boundary layer streaming. Streaming increases with velocity nonlinearities [Kranenburg et al., 2012] and effectively contributes to sediment transport [Dohmen-Janssen and Hanes, 2002]. According to the numerical simulations of Yu et al. [2010], streaming can enhance transport up to $40 \%$ of the total transport in the surf zone, even though nonlinear wave shape effects are dominant for grain sizes larger than $0.25 \mathrm{~mm}$. Furthermore, as already pointed out, near-bed phase lead and attenuation factor are key parameters. The variation of these two parameters with respect to the cross-shore position should be investigated to determine if this method can give reasonable results anywhere inside the surf zone.

[52] The simple phenomenological model based on (10) and (12) of section 2 shows that the linear relationship between skewness and asymmetry seems to have a higher degree of generality. This model is based on a few assumptions. Firstly, the velocity shape in the surf-zone given by (12) needs to be more thoroughly assessed. Secondly, the model assumes that the boundary layer reacts linearly which is of course the case for laminar boundary layers but, given the nature of turbulence, is not true in turbulent boundary layers. Future work should therefore address the issue of how higher Reynolds number forcing will affect this relation between free-stream asymmetry and near-bed skewness. The field measurements by Foster et al., [2000, see Figure 10] or by Henderson et al. [2004] combined with a $k-\epsilon$ model as well as the numerical study by Fuhrman et al. [2009] tend to indicate that our analysis is also relevant to wave forcing at high Reynolds numbers.

[53] Acknowledgments. The technical support of Jean-Marc Barnoud, Muriel Lagauzère, and Pierre-Alain Barraud is gratefully acknowledged. The first author's PhD was funded by the French ministry MESR and Grenoble INP. This study was partly funded by the project MODLIT (DGA-SHOM/INSU-RELIEFS) and the project BARCAN (INSU-LEFE). The authors are grateful to the reviewers and the associate editor for comments that led to significant improvements of the article.

\section{References}

Abreu, T., P. A. Silva, F. Sancho, and A. Temperville (2010), Analytical approximate wave form for asymmetric waves, Coast. Eng., 57, 656-667.

Abreu, T., H. Michallet, P. A. Silva, F. Sancho, D. van der A, and B. G. Ruessink (2013), Bed shear stress under skewed and asymmetric oscillatory flows, Coast. Eng., 73, 1-10. 
Berni, C., H. Michallet, and E. Barthélemy (2012), Measurements of surf zone sand bed dynamics under irregular waves, Eur. J. Environ. Civ. Eng., 16(8), 981-994, doi:10.1080/19648189.2012.705957.

Bonneton, P., E. Barthélemy, F. Chazel, R. Cienfuegos, D. Lannes, F. Marche, and M. Tissier (2011), Recent advances in Serre-Green Naghdi modelling for wave transformation, breaking and runup processes, Eur. J. Mechanics B/Fluids, 30, 589-597.

Briganti, R., N. Dodd, D. Pokrajac, and T. O’Donoghue (2011), Non linear shallow water modelling of bore-driven swash: Description of the bottom boundary layer, Coast. Eng., 58, 463-477.

Dibajnia, M., and A. Watanabe (1992), Sheet flow under nonlinear waves and currents, in Proceedings of the International Conference on Coastal Engineering, 2015-2028, Venice, Italy, October 4-9, ASCE.

Dick, J. E., and J. F. A. Sleath (1991), Velocities and concentrations in oscillatory flow over beds of sediment, J. Fluid Mech., 233, 165-196.

Dohmen-Janssen, C. M., and D. M. Hanes (2002), Sheet flow dynamics under monochromatic nonbreaking waves, J. Geophys. Res., 107, 13, $1-13$.

Dohmen-Janssen, C. M., D. F. Kroekenstoel, W. N. Hassan, and J. S. Ribberink (2002), Phase lags in oscillatory sheet flow: Experiments and bed load modelling, Coast. Eng., 46, 61-87.

Drake, T. G., and J. Calantoni (2001), Discrete particle model for sheet flow sediment transport in the nearshore, J. Geophys. Res., 106, 19,859-19,868

Elfrink, B., D. M. Hanes, and B. G. Ruessink (2006), Parametrization and simulation of near bed orbital velocities under irregular waves in shallow water, Coast. Eng., 53, 915-927.

Elgar, S., and R. T. Guza (1985), Observations of bispectra of shoaling surface gravity waves, J. Fluid Mech., 161, 425-448, doi: $10.1017 / \mathrm{S} 0022112085003007$.

Elgar, S. (1987), Relationships involving third moments and bispectra of a harmonic process, IEEE Trans. on Acoust. Speech, and Signal Processing, ASSP-35, 12.

Elgar, S., E. L. Gallagher, and R. T. Guza (2001), Nearshore sand bar migration, J. Geophys. Res., 106(C06), 11,623-11,627.

Ferguson, R. I., and M. Church (2004), A simple universal equation for grain settling velocity, J. Sed. Res., 74(6), 933-937.

Foster, D. L., R. A. Beach, and R. A. Holman (2000), Field observation of the wave bottom boundary layer, J. Geophys. Res., 105(C8), $19,631-19,647$

Fuhrman, D. R., J. Fredsøe, and B. M. Sumer (2009), Bed slope effects on turbulent wave boundary layers: 2. Comparison with skewness, asymmetry, and other effects, J. Geophys. Res., 114, C03025, doi: 10.1029/2008JC005053.

Grasso, F., H. Michallet, E. Barthélemy, and R. Certain (2009), Physical modeling of intermediate cross-shore beach morphology: Transients and equilibrium states, J. Geophys. Res., 114, C09001, doi: 10.1029/2009JC005308.

Grasso, F., H. Michallet, and E. Barthélemy (2011a), Experimental simulation of shoreface nourishments under storm events: A morphological, hydrodynamic, and sediment grain size analysis, Coast. Eng., 58(2), 184-193.

Grasso, F., H. Michallet, and E. Barthélemy (2011b), Sediment transport associated with morphological beach changes forced by irregular asymmetric, skewed waves, J. Geophys. Res., 116, C03020, doi: 10.1029/2010JC006550.

Henderson, S. M., J. S. Allen, and P. A. Newberger (2004), Nearshore sandbar migration predicted by an eddy-diffusive boundary layer model, $J$. Geophys. Res., 109, C05025

Henriquez, M., A. Reniers, G. Ruessink, and M. Stive (2010), Wave boundary layer hydrodynamics during onshore bar migration, in Proceedings of the 32nd International Conference on Coastal Engineering., Shanghai, China.

Hsu, T. J., and D. M. Hanes (2004), Effects of wave shape on sheet flow sediment transport, J. Geophys. Res., 109, C05025, doi: $10.1029 / 2003 \mathrm{JC} 002075$.

Hurther, D. (2001), 3-D acoustic Doppler velocimetry and turbulence in open-channel flow, Ph.D. thesis, Ecole Polytechnique Fédérale de Lausanne, Lausanne, Switzerland.

Hurther, D., and P. D. Thorne (2011), Suspension and near-bed load sediment transport processes above a migrating, sand-rippled bed under shoaling waves, J. Geophys. Res., 116, C07001, doi: 10.1029/ 2010JC006774.

Jensen, B. L., B. M. Sumer, and J. Fredsoe (1989), Turbulent oscillatory boundary layers at high Reynolds numbers, J. Fluid Mech., 206, $265-297$.
Jonsson, I. G., and N. A. Carlsen (1976), Experimental and theoretical investigations in an oscillatory turbulent boundary layer, J. Hydraul. Res., 14, 45-60.

King, D. B. (1991), Studies in oscillatory flow bedload sediment transport, Ph.D. thesis, Univ. of Calif., San Diego.

Kirby, J. T., H. T. Özkan-Haller, and M. C. Haller (2006), Seiching in a large wave flume, in Proceedings of the International Conference on Coastal Engineering, 1159-1171, San Diego, CA.

Kranenburg, W. M., J. S. Ribberink, R. E. Uittenbogaard, and S. J. M. H. Hulscher (2012), Net currents in the wave bottom boundary layer: On waveshape streaming and progressive wave streaming, J. Geophys. Res., 117, F03005, doi:10.1029/2011JF002070.

Lippmann, T. C., and R. A. Holman (1990), The spatial and temporal variability of sand bar morphology, J. Geophys. Res., 95(C7), 11,575-11,590, doi:10.1029/JC095iC07p11575.

Michallet, H., R. Cienfuegos, E. Barthélemy, and F. Grasso (2011), Kinematics of waves propagating and breaking on a barred beach, Eur. J. Mechanics B/Fluids, 30, 624-634.

Nielsen, P. (1992), Coastal Bottom Boundary Layers and Sediment Transport, p. 324, World Sci., Singapore.

Nielsen, P. (2006), Sheet flow sediment transport under waves with acceleration skewness and boundary layer streaming, Coast. Eng., 53, 749-758.

O'Donoghue, T., and S. Wright (2004), Flow tunnel measurements of velocities and sand flux in oscillatory sheet flow for well-sorted and graded sands, Coast. Eng., 51, 1163-1184.

O’Donoghue, T., D. Pokrajac, and L. J. Hondebrink (2010), Laboratory and numerical study of dambreak-generated swash on impermeable slopes, Coast. Eng., 57(5), 513-530.

Ruessink, B. G., H. Michallet, T. Abreu, F. Sancho, D. A. Van der A, J. J. Van der Werf, and P. A. Silva (2011), Observations of velocities, sand concentrations, and fluxes under velocity-asymmetric oscillatory flows, J. Geophys. Res., 116, C03004, doi:10.1029/2010JC006443.

Ruessink, B. G., G. Ramaekers, and L. C. van Rijn (2012), On the parameterization of the free-stream non-linear wave orbital motion in nearshore morphodynamic models, Coast. Eng., 65, 56-63.

Silva, P. A., T. Abreu, H. Michallet, D. Hurther, and F. Sancho (2009), Sheet flow layer structure under oscillatory flow, in River, Coastal and Estuarine Morphodynamics, 1057-1062, Santa Fe, Argentina.

Sleath, J. F. A. (1987), Turbulent oscillatory flow over rough beds, J. Fluid Mech., 182, 369-409.

Sparrow, K., D. Pokrajac, and D. van der A (2012), The effect of bed permeability on oscillatory boundary layer flow, in Proceedings of the International Conference on Coastal Engineering, Santander, Spain, 723.

Stokes, G. G. (1851), On the effect of the internal friction of fluids on the motion of pendulums, Trans. Camb. Phil. Soc., 9, 20-21.

Suntoyo, H. Tanaka, and A. Sana (2008), Characteristics of turbulent boundary layers over a rough bed under saw-tooth waves and its application to sediment transport, Coast. Eng., 55(12), 1102-1112.

Suntoyo, and H. Tanaka (2009), Effects of bed roughness on turbulent boundary layer and net sediment transport under asymmetric waves, Coast. Eng., 56, 960-969.

Swart, D. H. (1974), Offshore sediment transport and equilibrium beach profiles, Delft Hydraul. Lab., Publ. 131, Delft Hydraul., The Netherlands.

Terrile, E., A. J. H. M. Reniers, and M. J. F. Stive (2009), Acceleration and skewness effects on the instantaneous bed-shear stresses in shoaling waves, J. Waterway, Port, Coastal, Ocean Eng., 135, $228-234$.

van der A, D. A., T. O’Donoghue, and J. S. Ribberink (2010), Measurements of sheet flow transport in acceleration-skewed oscillatory flow and comparison with practical formulations, Coast. Eng., 57, $331-342$.

van der A, D. A., T. O’Donoghue, A. G. Davies, and J. S. Ribberink (2011), Experimental study of the turbulent boundary layer in accelerationskewed oscillatory flow, J. Fluid Mech., 684, 251-283.

Wilson, K. C. (1989), Mobile-bed friction at high shear stress, J. Hydraul. Eng., 115(6), 825-830.

Wilson, K. C. (1987), Analysis of bed-load motion at high shear stress, $J$. Hydraul. Eng., 113(1), 97-103.

Yu, X., T. J. Hsu, and D. M. Hanes (2010), Sediment transport under wave groups: Relative importance between nonlinear waveshape and nonlinear boundary layer streaming, J. Geophys. Res., 115, C02013.

Zhang, C., J. Zheng, Y. Wang, and Z. Demirbilek (2011), Modeling wavecurrent bottom boundary layers beneath shoaling and breaking waves, Geo-Mar Lett., 31(3), 189-201. 